Case report

\title{
Caecum perforation and SARS COV-2 infection: More than association?
}

Aguilar Leonel Castellanos ${ }^{1 *}$, Duran Edwing Michel Jaimes ${ }^{1}$, Lorenzana Roberto Heras.
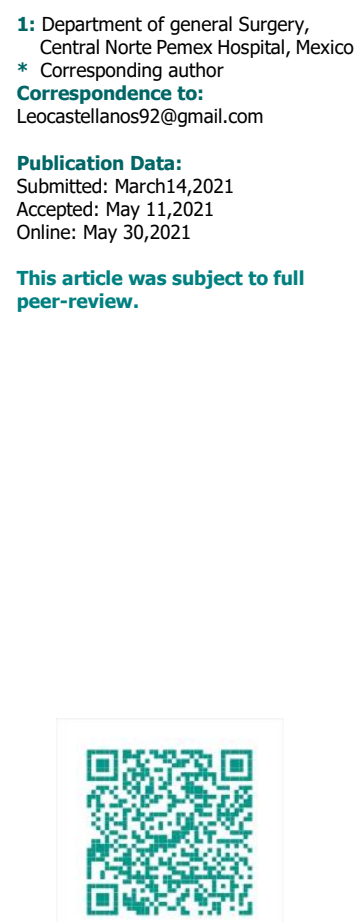

This is an open access article distributed under the terms of the Creative Common Attribution Non-Commercial License 4.0 (CCBY-NC) allowing sharing and adapting. Share: copy and redistribute the material in any medium or format. Adapt: remix, transform, and build upon the licensed material.

\section{Abstract}

Severe acute respiratory syndrome coronavirus 2 (SARS-COV-2) infection is a worldwide pandemic involving more than 150 million people. The coronavirus disease 2019 (COVID19) predominantly presents as a respiratory tract infection that may lead to acute respiratory distress. Gastrointestinal (GI) manifestations have been reported in several Chinese studies about SARS COV-2 infection. The most frequently reported GI symptoms are nausea, vomiting, diarrhea, and abdominal pain [1]. Bowel perforation was rarely reported in less than 20 cases [2]. We herein report the case of caecum perforation in severely infected female patient.

\section{Keywords:}

SARS COV-2; Colon perforation; Intensive care.

\section{Introduction}

The GI perforation in critically ill patients was described and classified before the outbreak of the COVID-19 pandemic as one of the complications of long intensive care unit management [2]. However, a possible direct action of the virus on the digestive tract has been proved. The presence of viral materials in the feces and receptors similarities that allow the virus to bind the enterocyte surface could be arguments of some direct interference of the disease with severe GI presentations [3].

\section{Observation}

A 48-year-old female obese patient presented to the emergency department (ED) for headache, fever and myalgias of six days evolution. On the examination the patient was vitally stable with mild tachypnea and desaturation. Nasopharyngeal swab tested positive for SARS-CoV-2 polymerase chain reaction (PCR).

The patient was hospitalized, and treatment was started according to the local protocol. During her hospitalization, she presented gradual respiratory deterioration and was shifted to ICU, intubated, and mechanically ventilated. Diarrheal evacuations were noted, and the patient was kept on parenteral nutrition. Respiratory improvement allowed gradual sedation to decrease, and the patient was extubated two days later. Oral diet was started with acceptable tolerance and patient was candidate for discharge.

However, she presented suddenly with acute abdomen and hemodynamic deterioration. Computed tomography (CT) of the abdomen and pelvis confirmed acute peritonitis and bowel perforation. The patient underwent emergency laparotomy. The findings were in favor of fecal peritonitis due to a large $4 \mathrm{~cm}$ perforation the caecum wall (figure1). Peritoneal lavage, hemicolectomy and, ileocolostomy were performed. The postoperative course was marked by persistent and severe septic shock which led to death on the fourth postoperative day. The histopathological examination of the colon specimen was in favor of ischemic enterocolitis and ileum lymphoid sinusoidal hyperplasia (figure2). 

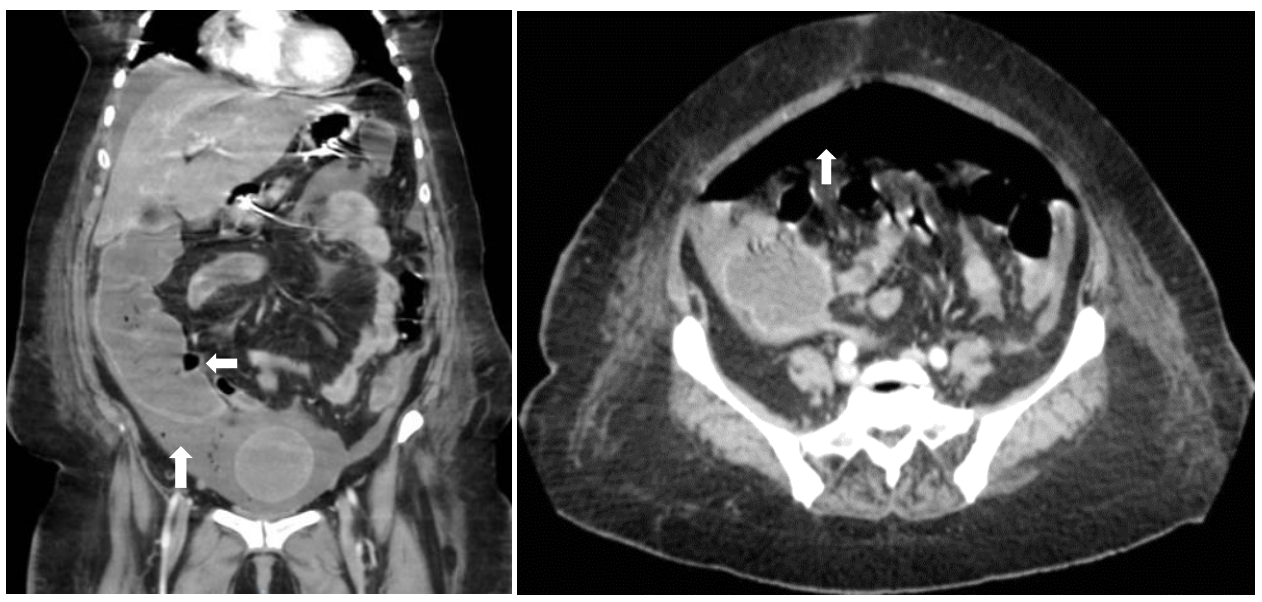

Figure 1: CT abdomen showing right paracolic gutter and pelvic collections with extra-digestive free air.

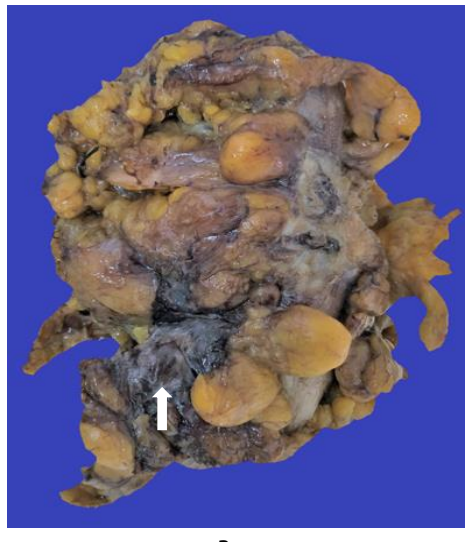

a

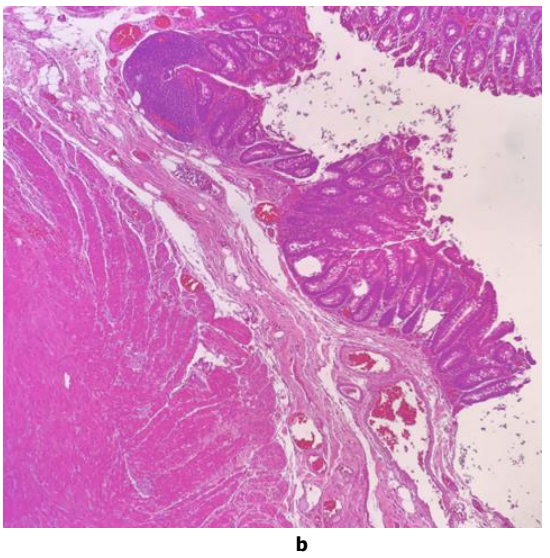

b

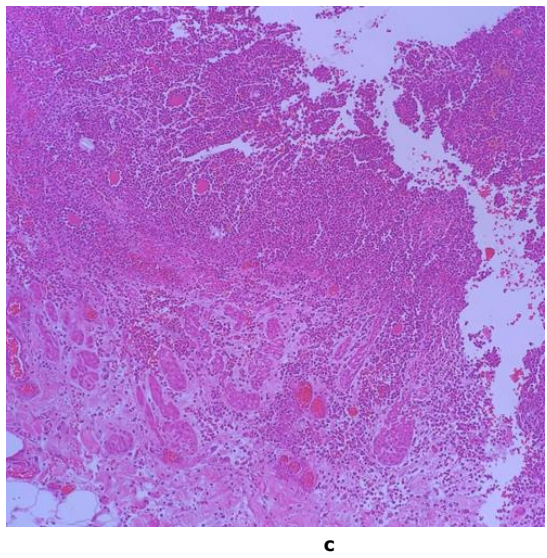

c

Figure 2: histopathological examination findings

a: large perforation in the posterolateral caecum wall
$b, c:$ ischemic mucosal features with vascular congestion and neutrophilic infiltration of the submucosa, and eosinophilia of the muscularis propria (HE, $4 x$ ).

\section{Discussion}

The GI manifestations are the most frequently reported extra-pulmonary manifestations of COVID-19 disease. It has been reported that found that $17.6 \%$ cases had digestive symptoms. Virus RNA was detected in stool samples from $48.1 \%$ patients, even those tested negatives for respiratory samples [3]. Acute surgical abdomen due to bowel perforation was usually fatal in the previously reported cases. Considered first as associated, GI symptoms have been confirmed as the result of direct interaction between the coronavirus and the digestive tract. The receptor for Angiotensin Converting Enzyme 2 (ECA2) and proteases of endogenous serine may allow virus fixation to the enterocyte membranes and its infection [4]. However, the severity of GI symptoms was never correlated the viral load suggesting a multifactorial phenomenon that may lead to severe complications specially bowel perforation [5]. COVID-19 ischemic colitis is characterized by transmural inflammatory infiltration. It may be the result of extended colonic pseudo-obstruction (Ogilvie syndrome). Most of the reported cases were associated with 
pulmonary lesions and hypercoagulability. Intramural thrombi formation affects the parietal blood supply and may constitute the primum movens of the ischemic process. Mesenteric and portal vein thrombosis might contribute to GI lesions in some cases. Ischemic bowel wall further induces a massive spread of the viruses $[6,7]$. Some other authors suggested an indirect effect of the immunomodulation created by the long steroid and anti-interleukin 6 receptor monoclonal antibodies treatment used worldwide in the treatment of this disease [8,9]. Spontaneous stercoral or idiopathic perforation colonic injury are also to be discussed. However, the perforation mechanisms might be more complex and involve underlaying personal factors in some reported cases. The direct mediation of the virus seems to be plausible but needs more investigation to be confirmed.

\section{Conflict of Interest: None}

\section{References}

[1] Xiao F, Tang M, Zheng X, Liu Y, Li X, Shan H. Evidence for gastrointestinal infection of SARS-CoV-2. Gastroenterology. 2020; 158:1831-33.

[2] Cipriano M, Ruberti E, Giacalone A. Gastrointestinal infection could be new focus for Coronavirus diagnosis. Cureus. 2020 ;12: e7422

[3] Cheung KS, Hung IFN, Chan PPY, Lung KC, Tso E, Liu R, et al. Gastrointestinal manifestations of SARS-CoV-2 infection and virus load in fecal samples from a Hong Kong cohort: Systematic review and meta-analysis. Gastroenterology. 2020; 159:81-95.

[4] Hamming I, Timens W, Bulthuis ML, Lely AT, Navis G, van Goor H. Tissue distribution of ACE2 protein, the functional receptor for SARS coronavirus. A first step in understanding SARS pathogenesis. J Pathol. 2004; 203:631-37.

[5] Su S, Shen J, Zhu L, Qiu Y, He JS, Tan JY, et al. Involvement of digestive system in COVID-19: manifestations, pathology, management and challenges. Therap Adv Gastroenterol. 2020; 13:1756284820934626.

[6] Ignat M, Philouze G, Aussenac-Belle L, Faucher V, Collange O, Mutter D, et al. Small bowel ischemia and SARS-CoV-2 infection: an underdiagnosed distinct clinical entity. Surgery. 2020; 168:14-16.

[7] Shaikh DH, Patel H, Makker J, Badipatla K, Chilimuri S. Colonic ileus, distension, and ischemia due to COVID-19-related colitis: A case report and literature review. Cureus. 2021;13: e13236.

[8] Schwab K, Hamidi S, Chung A, Lim RJ, Khanlou N, Hoesterey D, et al. Occult colonic perforation in a patient with Coronavirus disease 2019 after Interleukin-6 receptor antagonist therapy. Open Forum Infect Dis. $2020 ; 7$ : ofaa424

[9] Lamers MM, Beumer J, van der Vaart J, Knoops K, Puschhof J, et al. SARS-CoV-2 productively infects human gut enterocytes. Science. 2020; 369:50-54. 